\title{
EUROPEAN CALL OPTION APPLICATION IN INCOMPLETE MARKET-ANALYSIS AND DEVELOPMENT
}

\author{
Ro'fah Nur Rachmawati, Sufon and Widodo Budiharto
}

Department of Computer Science and Mathematics, Bina Nusantara University, Jakarta, Indonesia

Received 2013-09-18, Revised 2013-10-02; Accepted 2013-11-12

\begin{abstract}
Option is derivative instrument that have investment benefit and provide return for the writer and the holder. Option price determination is affected by risk factor. However in Black-Scholes model option price is determined without arbitrage risk affection so it is impossible to take return. In this study, option price formula is constructed to be more represent the condition of financial market using incomplete market concept where financial asset, that is traded, is affected by arbitrage risk so it is possible for market participants to take return. European call option is defined by Esscher Transform method and option price formula is determined by changing its form to linear approximation. The result from this study is option price formula with linear approximation has some privileges. That is easy to be applied in computation process, more representatives in getting risk indication in the financial market and can predict option price more accurately. Linear approximation formula is applied in the program that can be used by option writer or holder and is equipped with export data feature that can be possible for further research development.
\end{abstract}

Keywords: European Call Option, Linear Approximation, Incomplete Market

\section{INTRODUCTION}

Pradhitya et al. (2012) states that: "Option is defined as a contract between two parties (issuer and the holder of the option) which gives the publisher the right but not the obligation to the holder of an option to buy (call option) or sell (put option) a stock with an agreed price in the future".

Option is a hedging instrument in investing. This instrument can be used in trading strategies, for example, to avoid the collapse of stock prices, shareholders may issue a call option so that the owner of the option can exercise his right to buy shares at the price stated in the option (Soesanto and Kaudin, 2008). Therefore, to ensure the benefits of publishing option, we would require the model to calculate the estimated value of an option. The most classic models and the most popular type calculate European option pricing is the BlackScholes models, where the yield (return) of the assets sold by the end of the period assumed to be normally distributed (Gerber and Landry, 1997). Soesanto and Kaudin (2008) state that the assumptions used in the
Black-Scholes model is not realistic and its validity is questionable. This model assumes the absence of risk factors in arbitrage (Floroiu and Pelsser, 2012). It is certainly not possible in a real situation. However, the Black-Scholes option pricing model is still often used as a reference for publishers to determine the option price and the option holder to determine whether to buy or sell options issued by publisher (Andriyanto, 2009).

A condition that exists in trading stocks is grouped into two models; those are complete markets and incomplete markets. In Complete market, market players can make the exchange of goods or assets directly or indirectly in the absence of transaction costs that do not allow for arbitration even without risk arbitrage, where it is impossible in incomplete. Incomplete market is more complicated than complete market, where this model consists of uncertainty sources (Verchenko, 2010). From the perspective of theory, incomplete market is a complex learning (Staum, 2007), because market circumstances in the real world that is not affected by many factors remain that cannot be explained with certainty. Some experts have also proved that the state of Jakarta, Indonesia 
the financial markets is incomplete market as described Staum (2007). The complex scope of incomplete markets does not mean that the model cannot be calculated, many experts have examined that model using assumptions, which are almost close to reality.

In determining the price of the European call option, the option price will be in accordance with the market situation in which the smaller the exercise price the greater call option price and if the greater calculated risk the smaller the call option price. So in this study, call option price will be calculated with linear approximation so that the calculation of the European call option price almost resembles the situation in the market, where the model will be derived by the method of Esscher Transform. Esscher Transform is chosen because based on the conclusions of Ruban et al. (2010) which states that the method of Esscher Transform is a method for calculating the price of an asset that has risk. Yao (2001) also states that the method of Esscher Transform provides an option price calculation model, which is efficient and consistent.

Calculation of option prices will be very useful for investors and issuers to determine the appropriate decisions in traded options. Authors designed to restrict user login system that can use this application. $\mathrm{R}$ language will be used to calculate the statistical formula used by the European call option pricing model. This system is expected to help stock investors who want to hedge with options traded and perform calculations efficiently.

\subsection{Encountered Problems and Scopes}

- Research for the European option price calculation models mostly performed on the complete market based on the Black-Scholes method and research on models of incomplete markets is still fewer

- There is still no complete construction of the European call option price calculation with linear approximation in incomplete market models

- Mostly the calculation formula of European call option price is very complex, so that it is difficult to calculate manually. According to Gerber and Landry (1997) it is difficult to calculate European call option price with the exact solution for incomplete markets when skewness close to 0

- The absence of a system created to facilitate the computation

Will limit the scope of this research so that the discussion can be more focused and the purpose of writing can be achieved. The scopes include:

- European call option price is assumed to be a stochastic process with stationary and independent increments and the risk -free interest rate is constant in accordance with stated in (Gerber and Landry, 1997)

- According to Mcleod et al. (2012) many researchers use $\mathrm{R}$ language to perform statistical calculations. Then the simulation program of European call option on an incomplete market will be created using the $\mathrm{R}$ language assistance to perform calculations

- This study compares the results of the calculation of European call option with a linear approximation, shifted Gamma Process and shifted Inverse Gaussian Process with Black-Scholes model, which is more often used, to see that the calculation of the linear approximation is almost close to the BlackScholes when circumstances are made to resembles the Black-Scholes model

- This study also compares the results of calculations with the original data of option prices in the market. The simulation option pricing in financial markets is only done one time by using data of call option price of Microsoft stock

\section{RESEARCH METHODS}

Research methods are the stages that must be set before doing the research, so that research can be done directionally, clearly and efficiently. In practice, the process of research and program design depicted in the diagram Fig. 1.

\section{EUROPEAN OPTION CALL FORMULA CONSTRUCTION}

\subsection{Initial Assumptions}

This research will be used several assumptions to limit the scope of the study. Let $\mathrm{S}(\mathrm{t})$ is a non-dividend stock price in time $\mathrm{t}$. There is a stochastic process $\mathrm{X}(\mathrm{t})$, where $X(t)$ is a process which has stationary increments and independent increments, then the final value of the option at the time 0 defined as:

$$
S(t)=S(0) e^{x(t)}, t \geq 0
$$

Call option is defined as payoff function $\prod(s) \geq 0$ with maturity date $\tau$. At time $\tau$, option holder will get $\prod(S(\tau))$. In this research, it is assumed that $r$ is constant risk-free force of interest. So the option prices at time $t$ are defined as:

$\mathrm{e}^{-\mathrm{r}(\tau-\mathrm{t})} \mathrm{E}^{*}[\Pi(\mathrm{S}(\tau)) \mid \mathrm{S}(\mathrm{t})], 0 \leq \mathrm{t}<\tau$

* states that the expected value is taken based on equivalent martingale measure, where Equation (1) according to the observations of the stock price is: 


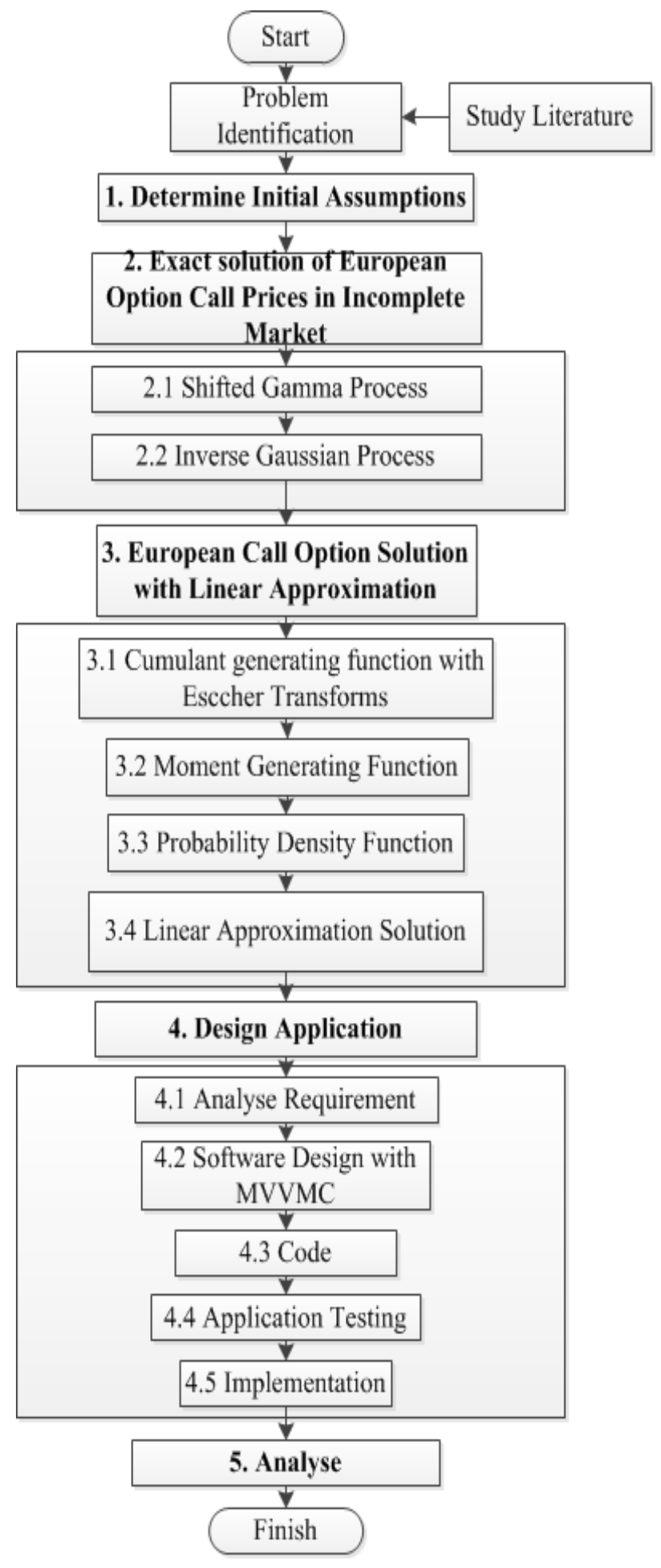

Fig. 1. Research method diagram

$$
\mathrm{S}(\mathrm{t})=\mathrm{e}^{-\mathrm{r}(\tau-\mathrm{t})} \mathrm{E}^{*}[(\mathrm{~S}(\tau)) \mid \mathrm{S}(\mathrm{t})], 0 \leq \mathrm{t}<\tau
$$

To simplify the calculations, then we will use $\tau=1$ and calculate the price of the option at time $t=0$ so that Equation (2) can be simplified to:

$$
1=\frac{e^{-r} E^{*}\left[S(0) e^{x(1)} \mid S(0)\right]}{S(0)}
$$

Because $\mathrm{S}(0)$ is deterministic, equation above become:

$$
1=e^{-r} E^{*}\left[e^{x(1)}\right]
$$

It is assumed $\mathrm{M}(\mathrm{z}, \mathrm{t})=\mathrm{E}\left[\mathrm{e}^{\mathrm{zx}(\mathrm{t})}\right]$ is a moment generating function for $\mathrm{X}(\mathrm{t})$, that is a condition where the expected value and volatility have never changed that satisfied:

$$
\mathrm{M}(\mathrm{z}, \mathrm{t})=\mathrm{M}(\mathrm{z})^{\mathrm{t}}, \mathrm{t}>0
$$

where $M(z)=M(z, 1)$ Equation (4 and 5):

$$
\begin{aligned}
& \mathrm{E}[\mathrm{X}(\mathrm{t})]=\mu \mathrm{t} \\
& \operatorname{Var}[\mathrm{X}(\mathrm{t})]=\sigma^{2} \mathrm{t} \\
& \mathrm{E}\left[(\mathrm{X}(\mathrm{t})-\mu \mathrm{t})^{3}\right]=\gamma \mathrm{t}
\end{aligned}
$$

In classic model, $\{\mathrm{X}(\mathrm{t})\}$ is Wiener process, where for $\mathrm{t}>0$, random variable of $\mathrm{X}(\mathrm{t})$ has normal distribution with mean $\mu \mathrm{t}$, variance $\sigma^{2} \mathrm{t}$ and $\gamma=0$. In this research it will be focused if $\gamma \neq 0$.

To get linear approximation solution, it will be assumed that $\{\mathrm{Y}(\mathrm{t})\}$ is a process that has stationer and independent increment with:

$$
\begin{aligned}
& \mathrm{E}[\mathrm{Y}(\mathrm{t})]=0 \\
& \operatorname{Var}[\mathrm{Y}(\mathrm{t})]=\mathrm{t} \\
& \mathrm{E}\left[\mathrm{Y}(\mathrm{t})^{3}\right]=t \\
& \mathrm{E}\left[\mathrm{e}^{\mathrm{zY}(\mathrm{t})}\right]=\mathrm{e}^{\mathrm{t} \psi(\mathrm{z})}
\end{aligned}
$$

Where Equation (6):

$$
\psi(\mathrm{z})=\frac{1}{2} \mathrm{z}^{2}+\frac{1}{6} \mathrm{z}^{3}+\ldots
$$


Construct with three-parameter-family that is defined as Equation (7):

$$
X(t)=k Y(\lambda t)+\mu t, t \geq 0
$$

With Equation (8):

$$
\mathrm{k}=\frac{\gamma}{\sigma^{2}}, \lambda=\frac{\sigma^{6}}{\gamma^{2}}
$$

So moment generating function of $\mathrm{X}(\mathrm{t})$ is Equation (9):

$$
\mathrm{M}(\mathrm{z}, \mathrm{t})=\exp \left(\mu \mathrm{z}+\frac{1}{2} \sigma^{2} \mathrm{z}^{2}+\frac{1}{6} \gamma \mathrm{z}^{3}+\ldots\right)
$$

\subsection{Exact Solution}

Exact solution for a European call option prices in incomplete markets will be constructed with the model developed by Gerber and Shiu (1994), using Gamma process model shifted and shifted inverse Gaussian process models. In the two models is defined $\mathrm{X}(\mathrm{t})$ and $\mathrm{Z}(\mathrm{t})$ is stochastic process that satisfy Equation (10):

$$
X(t)=Z(t)+c t
$$

Then defined moment generating function of $\mathrm{X}$ (1) Equation (11):

$$
\mathrm{E}\left[\mathrm{e}^{\mathrm{zX}(1)} ; \mathrm{h}\right]=\frac{\mathrm{M}(\mathrm{z}+\mathrm{h})}{\mathrm{M}(\mathrm{h})}=\mathrm{M}(\mathrm{z})
$$

Price of an option is defined as the expectation of the discounted payoff, where the expectation value is taken by Esscher transforms with parameter $h$, where the value $\mathrm{h}=\mathrm{h}^{*}$ and $\mathrm{z}=1$ is determined, so Equation (3) is satisfied. The we will get Equation (12):

$$
E^{*}\left[e^{X(1)} ; h^{*}\right]=e^{r}
$$

\subsection{Shifted Gamma Process Exact Solution}

In this model $\mathrm{Z}(\mathrm{t})$ is defined as Equation (10), assumed as a Gamma process with parameters $\alpha$ and $\beta$. Then the moment generating function of $X$ (1) based on shifted Gamma process model Equation (13):

$$
M\left(z ; h^{*}\right)=\left(\frac{\beta^{*}}{\beta^{*}-z}\right)^{\alpha} e^{-c z}, z<\beta-h^{*}
$$

So that (5) is satisfied, the value of $\alpha, \beta$ and $\mathrm{c}$ are given as follow:

$$
\alpha=\frac{4 \sigma^{6}}{\gamma^{2}} \beta=\frac{2 \sigma^{2}}{\gamma} c=\frac{2 \sigma^{4}}{\gamma}-\mu
$$

from (11), (12) and (13) we will get Equation (14):

$\beta^{*}=\left(1-\mathrm{e}^{-\frac{\mathrm{r}+\mathrm{c}}{\alpha}}\right)^{-1}$

So European call option with shifted Gamma process model is Equation (15):

$$
\begin{aligned}
& S(0)\left[1-G\left(\kappa+c ; \alpha, \beta^{*}-1\right)\right] \\
& -e^{r} K\left[1-G\left(\kappa+c ; \alpha, \beta^{*}\right)\right]
\end{aligned}
$$

where, $\mathrm{S}(0)=$ non dividend stock price at time $0, \mathrm{~K}=$ exercise price, $\mathrm{k}=\mathrm{In}[\mathrm{k} / \mathrm{S}(0)], \mathrm{r}=$ constant risk free force of interest, $\mathrm{G}($.$) = cumulative Gamma distribution$ function, $\beta^{*}=\left(1-\mathrm{e}-\frac{\mathrm{r}+\mathrm{c}}{\mathrm{a}}\right)^{-1}, \alpha=\frac{4 \sigma^{6}}{\gamma^{2}}, \mathrm{c}=\frac{2 \sigma^{4}}{\gamma}-\mu, \mu=$ mean, $\gamma=$ skewness.

\subsection{Shifted Inverse Gaussisan Process Exact Solution}

In this model $\mathrm{Z}(\mathrm{t})$ is defined as Equation (10), assumed as a Inverse Gaussian process with parameter a and $b$. Then the moment generating function of $X(1)$ based on Shifted Inverse Gaussian process is Equation (16):

$M\left(z ; h^{*}\right)=e^{a\left(\sqrt{b^{*}}-\sqrt{b^{*}-z}\right)-c z}, z<b^{*}$

So that (5) is satisfied, then the value of a,b and c are given as follow:

$a=3 \sqrt{\frac{6 \sigma^{10}}{\gamma^{3}}}, b=\frac{3 \sigma^{2}}{2 \gamma}, c=\frac{3 \sigma^{4}}{\gamma}-\mu$

From (11), (12) and (16) we will get Equation (17):

$b^{*}=\frac{\left[r^{2}+c^{2}+a^{2}+2 r c\right]^{2}}{4 a^{2}(r+c)^{2}}$

So that European call option with Shifted Inverse Gaussian process model is Equation (18):

$$
\begin{aligned}
& S(0)\left[1-J\left(\kappa+c ; a, b^{*}-1\right)\right] \\
& -e^{r} K\left[1-J\left(\kappa+c ; a, b^{*}\right)\right]
\end{aligned}
$$


where, $\mathrm{k}=\ln [\mathrm{K} / \mathrm{S}(0)], \mathrm{b}^{*}$ as in (17) and $\mathrm{J}($.$) is inverse$ Gaussian distribution function.

\section{LINEAR APPROXIMATION SOLUTION}

An equivalent martingale probability measure cannot be proved definitely applies in incomplete market models. But by Gerber and Shiu (1994), to get a unique answer, equivalent martingale measure will be limited to the method of Esscher transforms. By Esscher transforms with parameter $\mathrm{h}, \mathrm{X}(\mathrm{t})$ is defined as a stochastic process with the moment generating function of $\mathrm{X}(1)$ is defined as follows Equation (19):

$$
\mathrm{E}\left[\mathrm{e}^{\mathrm{zX}(1)} ; \mathrm{h}\right]=\frac{\mathrm{M}(\mathrm{z}+\mathrm{h})}{\mathrm{M}(\mathrm{h})}
$$

Price of an option is defined as the expectation of the discounted payoff, where the expectation value is taken by Esscher transforms with parameter $h$, where the value $\mathrm{h}=\mathrm{h}^{*}$ is determined so that Equation (3) are satisfied, then it will be obtained Equation (20):

$$
1=\mathrm{e}^{-\mathrm{r}} \mathrm{E}^{*}\left[\mathrm{e}^{\mathrm{x}(1)} ; \mathrm{h}^{*}\right]
$$

The process $\mathrm{X}(\mathrm{t})$ is assumed with Equation (7) where $\mathrm{k}$ and $\lambda$ as in (8). By Equation (9) and (19), cumulant generating function of $\mathrm{X}(1)$ on Esscher transforms with parameter h Equation (21):

$$
\begin{aligned}
& \ln \mathrm{E}\left[\mathrm{e}^{\mathrm{zX}(1)} ; \mathrm{h}\right] \\
& =\lambda[\psi(\mathrm{k}\{\mathrm{z}+\mathrm{h}\})-\psi(\mathrm{kh})]+\mu \mathrm{z}
\end{aligned}
$$

Substituted (6) in (22), then we will get Equation (22):

$$
\begin{aligned}
& \ln \mathrm{E}\left[\mathrm{e}^{\mathrm{zX}(1)} ; \mathrm{h}\right]=\lambda \frac{1}{2} \mathrm{k}^{2}\left[\mathrm{z}^{2}+2 \mathrm{hz}\right]+ \\
& \lambda \frac{1}{6} \mathrm{k}^{3}\left[\mathrm{z}^{3}+3 \mathrm{~h}^{2} \mathrm{z}+3 \mathrm{hz} \mathrm{z}^{2}\right]+\mu \mathrm{z}+\ldots
\end{aligned}
$$

Substituted $\mathrm{k}$ and $\lambda$ from (8) in (22), then we will get Equation (23):

$$
\begin{aligned}
& \ln \mathrm{E}\left[\mathrm{e}^{\mathrm{zX}(1)} ; \mathrm{h}\right]=\frac{1}{2} \sigma^{2}\left[\mathrm{z}^{2}+2 \mathrm{hz}\right]+ \\
& \frac{1}{6} \sigma^{2} \mathrm{k}\left[\mathrm{z}^{3}+3 \mathrm{~h}^{2} \mathrm{z}+3 \mathrm{hz} \mathrm{z}^{2}\right]+\mu \mathrm{z}+\ldots
\end{aligned}
$$

Based on (20) where $\mathrm{h}=\mathrm{h}^{*}$, (23) will become Equation (24):

$$
\begin{aligned}
& \frac{1}{2} \sigma^{2}\left[1+2 h^{*}\right]+\frac{1}{6} \sigma^{2} k\left[1+3 h^{*}+3 h^{* 2}\right] \\
& +\mu+\ldots-r=0
\end{aligned}
$$

$\mathrm{h}^{*}$ will be assumed as polynomial with variable $\mathrm{k}$, that is $\mathrm{h}^{*}=\mathrm{a}+\mathrm{bk}+\ldots$. This form will be substituted in (21) so that can be gotten as follow:

$$
\begin{aligned}
& \frac{1}{2} \sigma^{2}+\sigma^{2} a+\mu-r+ \\
& \left(\sigma^{2} b+\frac{1}{6} \sigma^{2}+\frac{1}{2} \sigma^{2} a+\frac{1}{2} \sigma^{2} a^{2}\right) \\
& k+\left(\frac{1}{2} \sigma^{2} b+\sigma^{2} a b\right) k^{2}+\ldots=0
\end{aligned}
$$

To make the above equation to be 0 , then the coefficient of each variable $\mathrm{k}$ will be made 0 . From the constants will be obtained from the following Equation (25):

$\mathrm{a}=\frac{\mathrm{r}-\mu}{\sigma^{2}}-\frac{1}{2}$

As for the coefficient $\mathrm{k}$, it will be obtained Equation (26):

$\mathrm{b}=-\frac{1}{6}\left(1+3 \mathrm{a}+3 \mathrm{a}^{2}\right)$

By changing $\mathrm{h}$ within (23), then we will get expansion of cumulant generating function of $\mathrm{X}(1)$ based on martingale measure Equation (27):

$$
\begin{aligned}
& \ln \mathrm{E}\left[\mathrm{e}^{\mathrm{zX}(1)} ; \mathrm{h}\right]=\frac{1}{2} \sigma^{2} \mathrm{z}^{2}+\sigma^{2} \mathrm{az}+\sigma^{2} \mathrm{bkz}+ \\
& \frac{\mathrm{k}}{6} \sigma^{2}\left(\mathrm{z}^{3}+3 \mathrm{az}^{2}+3 \mathrm{a}^{2} \mathrm{z}\right)+\mu \mathrm{z}+\cdots
\end{aligned}
$$

It is defined that $\mu^{*}=r-\frac{1}{2} \sigma^{2}$. (26) can be simplified and become Equation (28):

$$
\sigma^{2} \mathrm{a}-\mu=\mu^{*}
$$

Then within (27) will be substituted (28) and b with (26), so we will get Equation (29):

$$
\begin{aligned}
& \ln E\left[e^{\mathrm{zX}(1)} ; \mathrm{h}\right]=\mu^{*} \mathrm{z}+\frac{1}{2} \sigma^{2} \mathrm{z}^{2}+ \\
& \frac{\mathrm{k}}{6} \sigma^{2} \mathrm{z}^{3}+\frac{\mathrm{k}}{2} \sigma^{2} a z^{2}-\frac{\mathrm{k}}{2} \sigma^{2}\left(\frac{1}{3}+\mathrm{a}\right) \mathrm{z}+\cdots
\end{aligned}
$$


Assumed that $\mathrm{P}(\mathrm{z})$ an equation with a variable that contains some parts of the Equation (29) are defined as follows Equation (30):

$$
P(z)=\sigma^{2}\left(\frac{1}{6} z^{3}+\frac{1}{2} a z^{2}-\frac{1}{6} z-\frac{1}{2} a z\right)
$$

Within (30) a will be substituted with (25), then we will get $\mathrm{P}(\mathrm{z})$ as follow Equation (31):

$$
\begin{aligned}
& P(z)=\frac{1}{2}(r-\mu)\left(z^{2}-z\right) \\
& +\sigma^{2}\left(\frac{1}{12} z-\frac{1}{4} z^{2}+\frac{1}{6} z^{3}\right)
\end{aligned}
$$

Then (29) can be simplified and become Equation (32):

$$
\ln \mathrm{E}\left[\mathrm{e}^{\mathrm{zX}(1)} ; \mathrm{h}\right]=\mu^{*} \mathrm{z}+\frac{1}{2} \sigma^{2} \mathrm{z}^{2}+\mathrm{kP}(\mathrm{z})+\cdots
$$

From cumulant generating function in (32), we will get expansion of moment generating function of $\mathrm{X}(1)$ Equation (33):

$$
\left[\mathrm{e}^{\mathrm{zX}(1)} ; \mathrm{h}\right]=\exp \left[\mu^{*} \mathrm{z}+\frac{1}{2} \sigma^{2} \mathrm{z}^{2}\right] \exp [\mathrm{kP}(\mathrm{z})] \ldots
$$

By using Maclaurin series then $\exp [\mathrm{kP}(\mathrm{z})]$ will become Equation (34):

$$
\exp [\mathrm{kP}(\mathrm{z})]=1+\mathrm{kP}(\mathrm{z})+\frac{1}{2} \mathrm{k}^{2}(\mathrm{P}(\mathrm{z}))^{2}+\cdots
$$
(35):

By substituting (33) within (34), we will get Equation

$$
\mathrm{E}\left[\mathrm{e}^{\mathrm{zX}(1)} ; \mathrm{h}\right]=\exp \left[\mu^{*} \mathrm{z}+\frac{1}{2} \sigma^{2} \mathrm{z}^{2}\right](1+\mathrm{kP}(\mathrm{z})+\cdots)
$$

It can be seen in (35) that $\exp \left[\mu^{*} z+\frac{1}{2} \sigma^{2} z^{2}\right]$ is moment generating function of standard normal random variable. So that can be stated Equation (36):

$\exp \left[\mu^{*} z+\frac{1}{2} \sigma^{2} z^{2}\right]=E[\exp (z X)]$

where, $X=\sigma Z+\mu$ with mean $\mu$ and variance $\sigma^{2}$ Equation (37):

$$
\begin{aligned}
& E[\exp (z X)]= \\
& \int_{-\infty}^{\infty} e^{z x} \frac{1}{\sqrt{2 \pi} \sigma} \exp \left[-\frac{1}{2}\left(\frac{x-\mu^{*}}{\sigma}\right)^{2}\right] d x
\end{aligned}
$$

$\frac{1}{\sqrt{2 \pi}} \exp \left[-\frac{1}{2}\left(\frac{\mathrm{x}-\mu^{*}}{\sigma}\right)^{2}\right]$ is standard normal probability density function $\phi($.$) , so that (37) can be simplified and$ become Equation (38):

$$
\mathrm{E}[\exp (\mathrm{zX})]=\frac{1}{\sigma} \int_{-\infty}^{\infty} \mathrm{e}^{\mathrm{zx}} \phi\left(\frac{\mathrm{x}-\mu^{*}}{\sigma}\right) \mathrm{dx}
$$

Multiplied with z, then we will get Equation (39):

$$
\mathrm{zE}[\exp (\mathrm{zX})]=\frac{1}{\sigma} \int_{-\infty}^{\infty} \mathrm{ze}^{\mathrm{zx}} \phi\left(\frac{\mathrm{x}-\mu^{*}}{\sigma}\right) \mathrm{dx}
$$

Within equation above, there is $\mathrm{ze}^{\mathrm{zx}}$, that is derivative form of $\mathrm{e}^{\mathrm{zx}}$. By using partial integration, we will get:

$$
z E[\exp (z X)]=-\frac{1}{\sigma^{2}} \int_{-\infty}^{\infty} e^{z x} \phi^{\prime}\left(\frac{x-\mu^{*}}{\sigma}\right) d x
$$

By repeating it, it can be obtained a series as follow Equation (40):

$$
\begin{aligned}
& z^{n} E[\exp (z X)]=(-1)^{n} \frac{1}{\sigma^{n+1}} \\
& \int_{-\infty}^{\infty} e^{z x} \phi^{(n)}\left(\frac{x-\mu^{*}}{\sigma}\right) d x \\
& \text { for } n=0,1,2, \ldots
\end{aligned}
$$

Within (40), $(-1)^{\mathrm{n}} \frac{1}{\sigma^{\mathrm{n}+1}} \phi^{(\mathrm{n})}\left(\frac{\mathrm{x}-\mu^{*}}{\sigma}\right)$ can be changed into $\frac{1}{\sigma}(-D)^{\mathrm{n}} \phi\left(\frac{\mathrm{x}-\mu^{*}}{\sigma}\right)$ where $(\mathrm{D})^{\mathrm{n}}$ indicate the n-th derivative.

Based on (32) probability density function $\mathrm{X}(1)$ can be stated as follow Equation (41):

$$
\mathrm{f}_{0}(\mathrm{x})+\mathrm{kf}_{1}(\mathrm{x})+\cdots
$$

Where Equation (42):

$$
\mathrm{f}_{0}(\mathrm{x})=\frac{1}{\sigma} \phi\left(\frac{\mathrm{x}-\mu^{*}}{\sigma}\right)
$$


And Equation (43):

$$
\begin{aligned}
& \mathrm{f}_{1}(\mathrm{x})=\frac{1}{2}(\mathrm{r}-\mu)\left[\frac{1}{\sigma^{3}} \phi^{\prime}\left(\frac{\mathrm{x}-\mu^{*}}{\sigma}\right)+\frac{1}{\sigma^{2}} \phi^{\prime}\left(\frac{\mathrm{x}-\mu^{*}}{\sigma}\right)^{2}\right] \\
& -\frac{1}{12} \phi^{\prime}\left(\frac{\mathrm{x}-\mu^{*}}{\sigma}\right)-\frac{1}{4 \sigma} \phi^{\prime \prime}\left(\frac{\mathrm{x}-\mu^{*}}{\sigma}\right)-\frac{1}{6 \sigma^{2}} \phi^{\prime \prime}\left(\frac{\mathrm{x}-\mu^{*}}{\sigma}\right)
\end{aligned}
$$

By changing exact distribution of $\mathrm{X}(1)$ with the result that was gotten from linear approximation, then the formula of European call option as follow Equation (44):

$$
\begin{aligned}
& \mathrm{e}^{-\mathrm{r}} \mathrm{E}^{*}\left[\Pi\left(\mathrm{s}(0) \mathrm{e}^{\mathrm{x}(1)}\right)\right] \cong \\
& \mathrm{e}^{-\mathrm{r}} \int_{-\infty}^{\infty} \Pi\left(\mathrm{s}(0) \mathrm{e}^{\mathrm{x}}\right) \mathrm{f}_{0}(\mathrm{x}) \mathrm{dx}+ \\
& \mathrm{ke}^{-\mathrm{r}} \int_{-\infty}^{\infty} \Pi\left(\mathrm{s}(0) \mathrm{e}^{\mathrm{x}}\right) \mathrm{f}_{1}(\mathrm{x}) \mathrm{dx}
\end{aligned}
$$

where, $\mathrm{k}=\frac{\gamma}{\sigma^{2}}, \mathrm{f}_{0}(\mathrm{x})$ and $\mathrm{f}_{1}(\mathrm{x})$ as (41) and (42).

Based on definition of payoff function, to compute European call option prices, $\prod\left(\mathrm{S}(0) \mathrm{e}^{\mathrm{x}}\right)$ will be substituted by $S(0) e^{x}-K$ where $K$ is exercise price. So that the formula of European call option is Equation (45):

$$
\begin{aligned}
& e^{-r} E^{*}\left[\Pi\left(S(0) e^{x(1)}\right)\right] \cong e^{-r} \int_{k}^{\infty}\left(S(0) e^{x}-K\right) \\
& f_{0}(x) d x+k e^{-r} \int_{k}^{\infty}\left(S(0) e^{x}-K\right) f_{1}(x) d x
\end{aligned}
$$

where, $\kappa=\ln \left[\frac{\mathrm{K}}{\mathrm{S}(0)}\right]$.

By using the integral calculation and probability density function of normal distribution, first term of (45) can be decomposed into Equation (46):

$$
\begin{aligned}
& \mathrm{e}^{-\mathrm{r}} \int_{\mathrm{k}}^{\infty}\left(\mathrm{S}(0) \mathrm{e}^{\mathrm{x}}-\mathrm{K}\right) \mathrm{f}_{0}(\mathrm{x}) \mathrm{dx}=\mathrm{S}(0) \\
& {\left[1-\Phi\left(\frac{\mathrm{k}-\mathrm{r}-\frac{\sigma^{2}}{2}}{\sigma}\right)\right]-\mathrm{e}^{-\mathrm{r}} \mathrm{K}\left[1-\Phi\left(\frac{\mathrm{k}-\mathrm{r}+\frac{\sigma^{2}}{2}}{\sigma}\right)\right]}
\end{aligned}
$$

To get the solution of the second term of (45), it will be described first integral form as follows Equation (47):

$$
I_{n}=\frac{1}{\sigma} \int_{\kappa}^{\infty} \phi^{n}\left(\frac{x-\mu^{*}}{\sigma}\right) e^{x} d x
$$

By using the method of partial integral, the above formula can be transformed into recursive function as follows Equation (48):

$$
I_{n}=-\left[e^{\kappa} \phi^{n-1}\left(\frac{\kappa-\mu^{*}}{\sigma}\right)\right]-\sigma I_{n-1},
$$

for $\mathrm{n}=1,2,3, \ldots$

In this recursive function, $I_{0}$ is described as follow Equation (49):

$$
\mathrm{I}_{0}=\mathrm{e}^{\mathrm{r}}\left[1-\Phi\left(\frac{\kappa-\mathrm{r}-\frac{\sigma^{2}}{2}}{\sigma}\right)\right]
$$

By applying the recursive function (47) in the second term of formula (45) and combining it with Equation (46) will be obtained European call option pricing formula with linear approximation method, which can be written in full:

$$
\begin{aligned}
& \mathrm{S}(0)\left[1-\Phi\left(\frac{2 \kappa-2 \mathrm{r}-\sigma^{2}}{2 \sigma}\right)\right]-\mathrm{e}^{-\mathrm{r}} \mathrm{K} \\
& {\left[1-\Phi\left(\frac{2 \kappa-2 \mathrm{r}+\sigma^{2}}{2 \sigma}\right)\right]+\mathrm{ke}^{\kappa-\mathrm{r}} \mathrm{S}(0) \phi\left(\frac{2 \kappa-2 \mathrm{r}+\sigma^{2}}{2 \sigma}\right)} \\
& {\left[\left(\frac{6 \mathrm{r}-6 \mu-\sigma^{2}}{12 \sigma^{2}}\right)\left(\frac{2 \kappa-2 \mathrm{r}+\sigma^{2}}{2 \sigma}\right)+\frac{1}{6 \sigma}\left[\left(\frac{2 \kappa-2 \mathrm{r}+\sigma^{2}}{2 \sigma}\right)^{2}-1\right]\right]} \\
& +\mathrm{ke}^{-\mathrm{r}} \mathrm{K} \phi\left(\frac{2 \kappa-2 \mathrm{r}+\sigma^{2}}{2 \sigma}\right) \\
& {\left[\left(\frac{6 \mathrm{r}-6 \mu-\sigma^{2}}{12 \sigma}\right)-\left(\frac{2 \mathrm{r}-2 \mu-\sigma^{2}}{4 \sigma^{2}}\right)\right.} \\
& {\left[\left(\frac{2 \kappa-2 \mathrm{r}+\sigma^{2}}{2 \sigma}\right)-\frac{1}{6 \sigma}\left[\left(\frac{2 \kappa-2 \mathrm{r}+\sigma^{2}}{2 \sigma}\right)^{2}-1\right]\right]}
\end{aligned}
$$

Where:

$\mathrm{S}(0)=$ Non dividend stock price at time 0

$\mathrm{K}=$ Exercise price, $\mathrm{k}=\ln [\mathrm{K} / \mathrm{S}(0)]$

$\mathrm{r} \quad=$ Constant risk free force of interest

$\sigma^{2}=$ Variance

$\mu \quad=$ Mean

$\Phi()=$. Standard normal cumulative distribution function, $\mathrm{k}=\frac{\gamma}{\sigma^{2}}$

$\gamma=$ Skewness

$\Phi()=$. Standard normal probability density function

In the European call option pricing formula with linear approximation can be seen that the first term 
$\mathrm{S}(0)\left[1-\Phi\left(\frac{2 \kappa-2 \mathrm{r}-\sigma^{2}}{2 \sigma}\right)\right]-\mathrm{e}^{-\mathrm{r}} \mathrm{K}\left[1-\Phi\left(\frac{2 \kappa-2 \mathrm{r}-\sigma^{2}}{2 \sigma}\right)\right]$, is a formula of the Black-Scholes model. Then the last term of the European call option pricing formula with linear approximation method is the rate of change (Fig. 5-6) between European call option pricing formula BlackScholes model, where $\gamma=0$ and the European call option pricing formula with linear approximation method, where $\gamma$ $\neq 0$. It is found that "the Constant Elasticity of Variance (CEV) model does not offer a correct description of equity prices", Based on that observations together with the renowned contribution of stochastic volatility formulation to option pricing, it seems to be required to have a hybrid structure of local and stochastic volatility (Choi et al., 2013).

\section{APPLICATION DESIGN}

\subsection{Use Case Diagram}

In Fig. 2 depicted that the admin can do some things that begin with login. After going through the login process, admin can see the data of users, changing passwords, adding to new user, changing the data of user, delete data of user, see the instructions for using the application, see the information of application and end use application with logout process. Here is the use case diagram of developed application.
In Fig. 3 depicted that the user can do some things that begin with login. After going through the login process, a new user can perform calculations, change the password, see the instructions, see the information of the application, see the glossary of terms and end use application with logout process. Based on the experiments, the application program runs accurately with GUI as shown in Fig. 4. After the user performs the calculation process, a new user could see tables and graphs calculations. Users can also export tables to Microsoft Office Excel application after the user see the results table.

\subsection{Simulation}

Simulations were performed in Table 1-4 using the applications that have been made. The simulation results are shown in tabular form as follows.

By using original data obtained from Microsoft Corporation (MSFT), note that the price of MSFT stock on the market on April 23, 2013 were \$ 30.6 with a mean value and the volatility of the stock return data in 20102012 is 0.067535 and 0 . Interest rates observed on April $23^{\text {th }}, 2013$ is $0.25 \%$. Maturity date of the call option is 1 year. Skewness value used is 0.001 . Differences in the calculation of the call option price call option prices from finance.yahoo.com as follows.

A value of 0 in the model shifted inverse Gaussian suggests that this model is hard to quantify as proposed Gerber and Landry (1997).

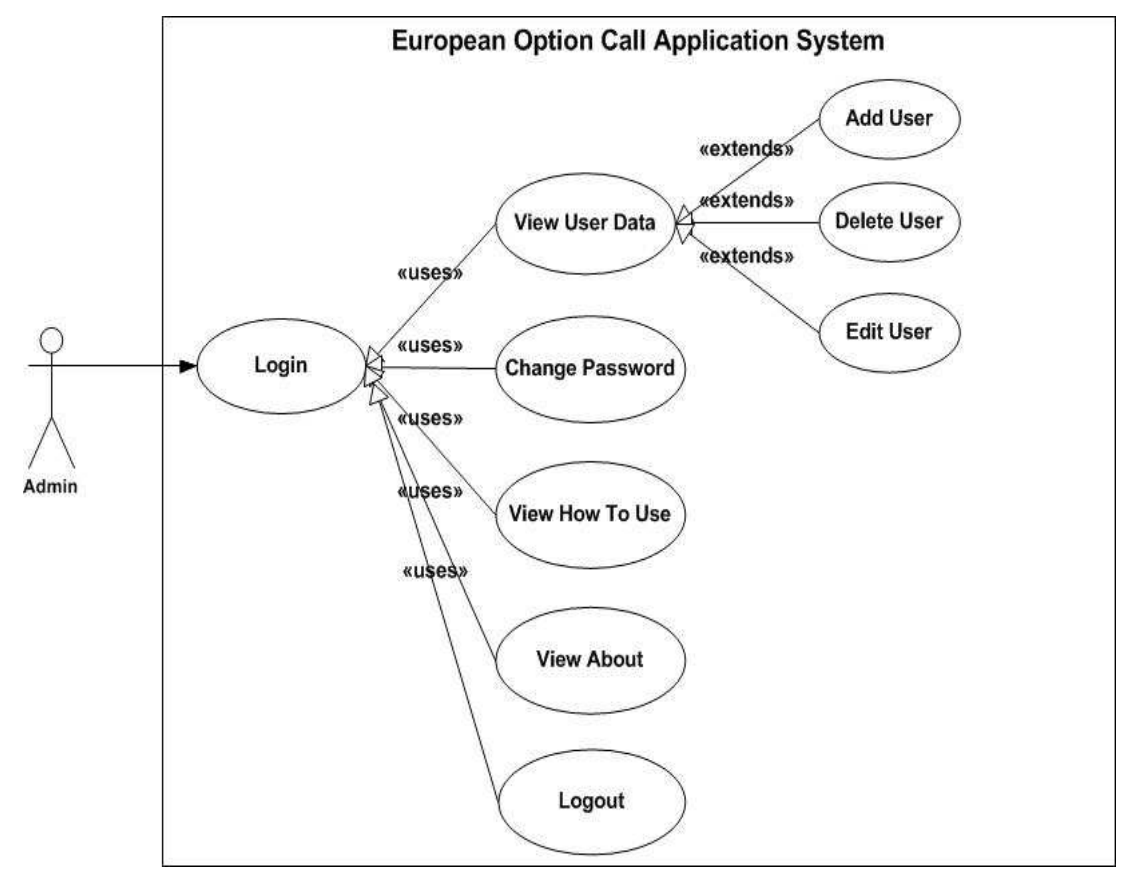

Fig. 2. Admin use case diagram 
Ro'fah Nur Rachmawati et al. / Journal of Computer Science 10 (1): 157-168, 2014

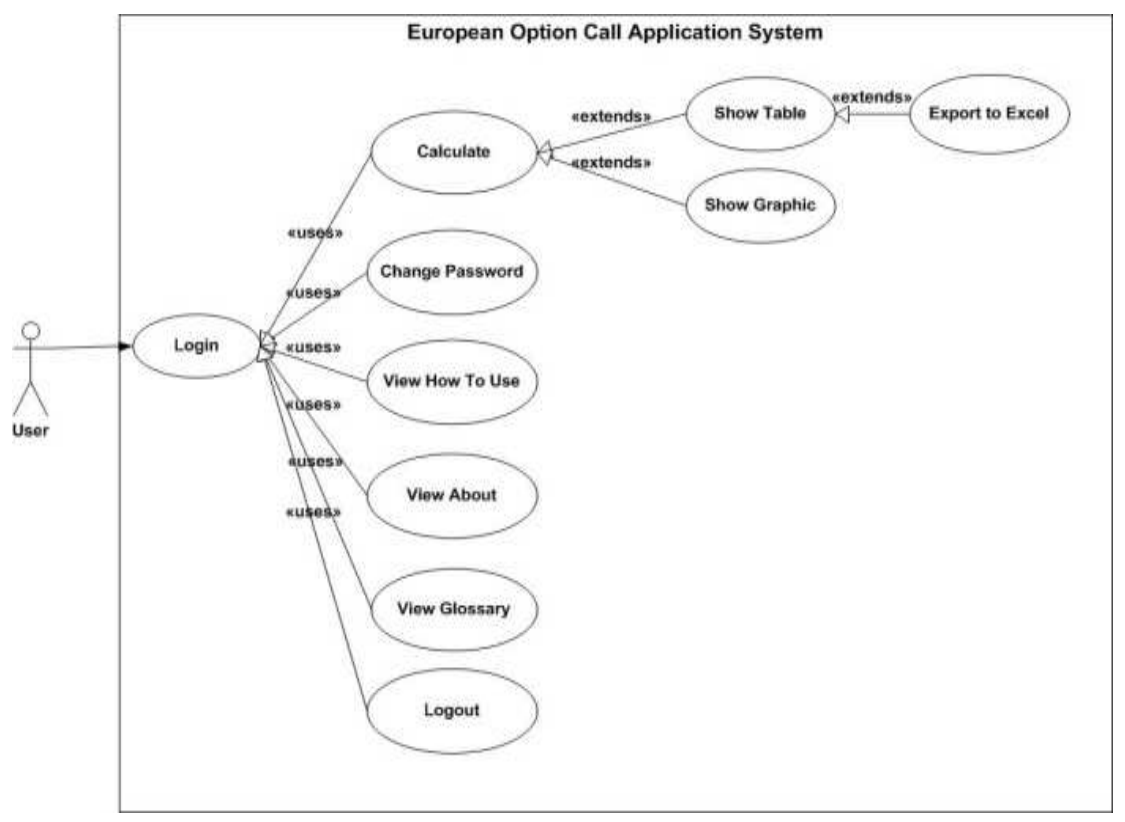

Fig. 3. User use case diagram

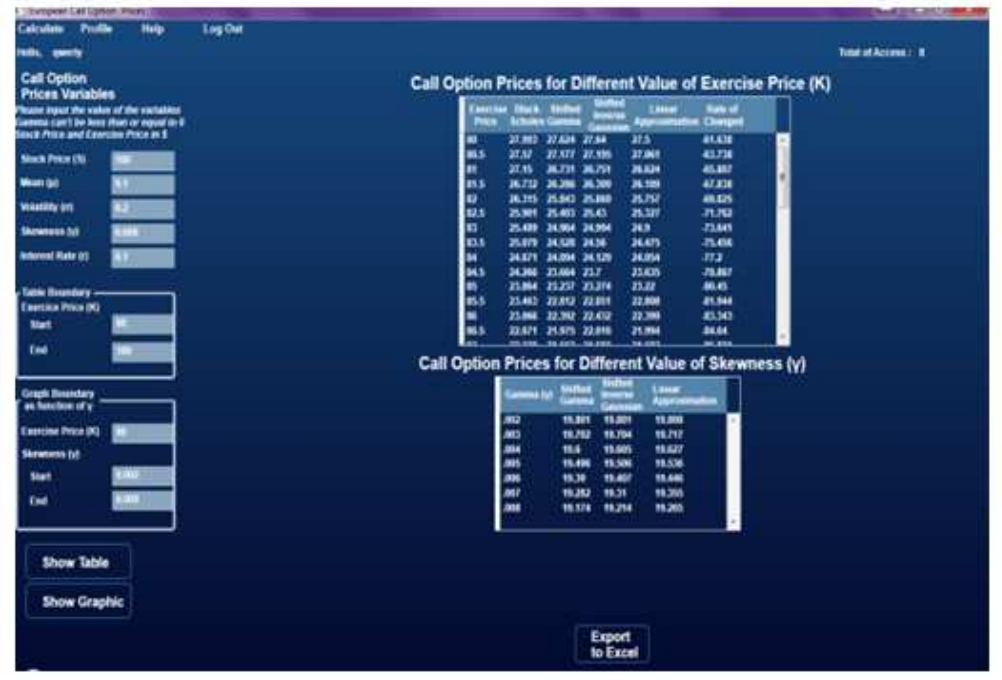

Fig. 4. Result of the application program

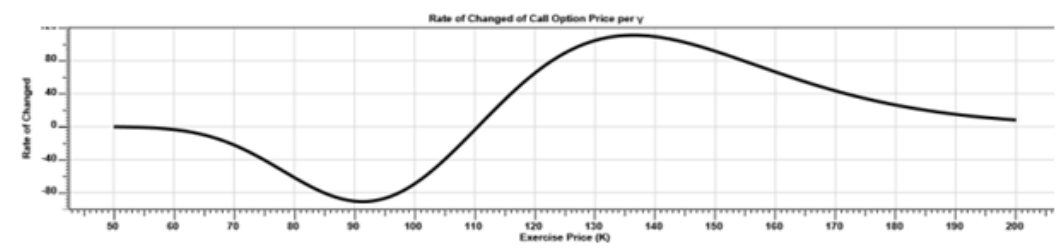

Fig. 5. Rate of Changed per $\gamma(r=0.1, \gamma=0.002)$ 


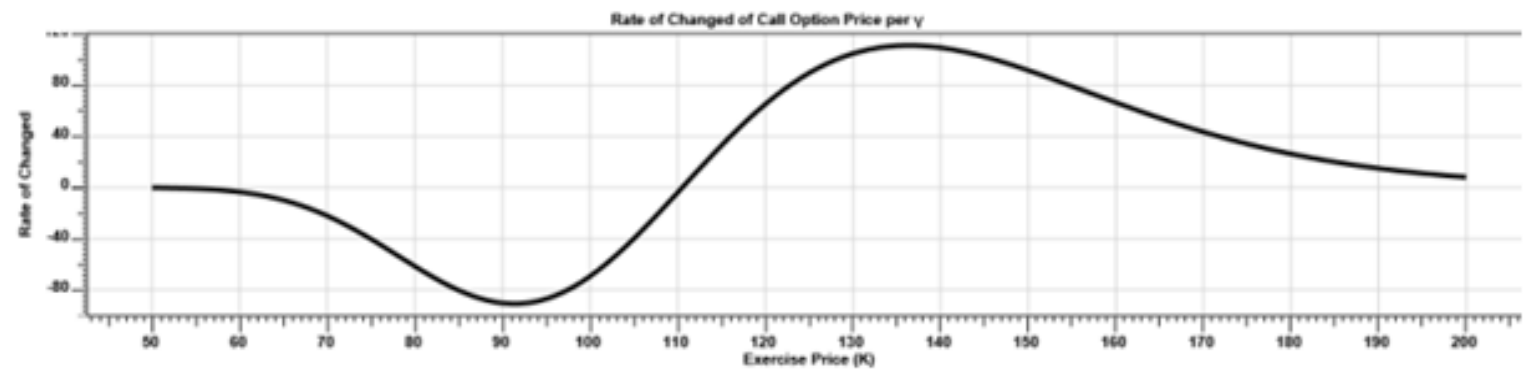

Fig. 6. Rate of Changed per $\gamma(r=0.1, \gamma=0.008)$

Table 1. European Option call price with $S=100, \mu=0,1, \sigma=0.2, \gamma=0.008, r=0.1$

\begin{tabular}{lllllr}
$\begin{array}{l}\text { Exercise } \\
\text { price }\end{array}$ & $\begin{array}{l}\text { Black- } \\
\text { scholes }\end{array}$ & $\begin{array}{l}\text { Shifted } \\
\text { gamma }\end{array}$ & $\begin{array}{l}\text { Shifted Inverse } \\
\text { gaussian }\end{array}$ & $\begin{array}{l}\text { Linear } \\
\text { approximation }\end{array}$ & $\begin{array}{l}\text { Rate of changed } \\
\text { at } \gamma=0\end{array}$ \\
\hline 80 & 27.99 & 27.62 & 27.64 & 27.500 & -61.6380 \\
85 & 23.86 & 23.24 & 23.27 & 23.220 & -80.4500 \\
90 & 19.99 & 19.17 & 19.21 & 19.260 & -90.4640 \\
95 & 16.44 & 15.59 & 15.61 & 15.740 & -87.1370 \\
100 & 13.27 & 12.55 & 12.54 & 12.710 & -69.4220 \\
105 & 10.52 & 10.03 & 10.01 & 10.200 & -39.9480 \\
110 & 8.18 & 7.99 & 7.95 & 8.152 & -3.8683 \\
115 & 6.26 & 6.35 & 6.31 & 6.522 & 32.8864 \\
120 & 4.71 & 5.05 & 5.01 & 5.230 & 65.1775 \\
\hline
\end{tabular}

Table 2. Percentage difference between Black Scholes model and others

\begin{tabular}{llcc}
\hline Exercise price & Shifted gamma & Shifted inverse gaussian & Linear approximation \\
\hline 80 & 1.34 & 1.27 & 1.78 \\
85 & 2.67 & 2.54 & 2.76 \\
90 & 4.28 & 4.06 & 3.79 \\
95 & 5.45 & 5.32 & 4.45 \\
100 & 5.74 & 5.82 & 4.41 \\
105 & 4.89 & 5.09 & 3.14 \\
110 & 2.38 & 2.89 & 0.34 \\
115 & -1.42 & -0.79 & -4.02 \\
120 & -6.73 & -5.99 & -9.94 \\
\hline
\end{tabular}

Table 3. Difference between calculated price and market price1

\begin{tabular}{lllrrr}
\hline Exercise price & Opsi Call di pasar & Black scholes & Error & Shifted gamma & Error \\
\hline 27 & 2.74 & 3.689 & 0.346 & 3.667 & 0.338 \\
27.5 & 3.70 & 3.212 & -0.132 & 3.169 & -0.144 \\
28 & 2.66 & 2.750 & 0.034 & 2.670 & 0.004 \\
28.5 & 2.15 & 2.311 & 0.075 & 2.171 & 0.010 \\
29 & 1.79 & 1.900 & 0.062 & 1.672 & -0.066 \\
29.5 & 1.16 & 1.527 & 0.316 & 1.210 & 0.043 \\
30 & 0.82 & 1.197 & 0.459 & 0.952 & 0.161 \\
30.5 & 0.34 & 0.913 & 1.685 & 0.771 & 1.269 \\
31 & 0.12 & 0.677 & 4.644 & 0.635 & 4.295 \\
\hline
\end{tabular}


Table 4. Difference between calculated price and market price2

\begin{tabular}{lllllr}
\hline Exercise price & Opsi call di pasar & Shifted inverse gaussian & Error & Linear Appro-ximation & Error \\
\hline 27 & 2.74 & 0.000 & 0.000 & 3.565 & 0.301 \\
27.5 & 3.70 & 0.000 & 0.000 & 3.040 & -0.178 \\
28 & 2.66 & 0.000 & 0.000 & 2.538 & -0.046 \\
28.5 & 2.15 & 0.000 & 0.000 & 2.078 & -0.033 \\
29 & 1.79 & 1.674 & -0.065 & 1.679 & -0.062 \\
29.5 & 1.16 & 1.260 & 0.086 & 1.354 & 0.167 \\
30 & 0.82 & 0.976 & 0.190 & 1.105 & 0.348 \\
30.5 & 0.34 & 0.775 & 1.279 & 0.924 & 1.719 \\
31 & 0.12 & 0.627 & 4.226 & 0.795 & 5.627 \\
\hline
\end{tabular}

This is because these models use the standard normal distribution, where if the skewness value the smaller the value of the normal distribution of raw getting closer to 0 so it is difficult to use in the calculation. Positive error value indicates calculated option price is above the market price and otherwise negative error shows the calculated option price is below the market price. The smaller the error value indicates that the calculated option price has little difference with the market price.

\section{CONCLUSION}

Based on the results of simulations that carried out with applications developed, we found some conclusions as follow:

- Formula of European call option price with linear approximation is an extension of Black-Scholes model where there is added value due to the skewness which showed the yield (return) of the underlying asset is not normally spread

- When the value of the skewness is getting close to 0 option pricing with linear approximation, shifted Gamma and shifted Inverse Gaussian get closer to Black-Scholes. Because the Black-Scholes model is widely used model to determine the option price so model of linear approximations can also be used to determine the option price

- Exact solution for the model of incomplete markets models shifted Gamma and Inverse Gaussian have proved difficult to use due to some specific cases where the value of the skewness is very small, with the option pricing model gives a value of 0 or undefined. This is due to the smaller size of the skew ness causes the value of the normal distribution used in the model shifted inverse Gaussian and the small value of the gamma distribution used in the model shifted Gamma.
When the value of the distribution is getting closer to 0 then the option price is calculated using the two models would be 0 or undefined. In contrast to the solution of linear models with incomplete market that is still able to calculate the option price when the value of the coefficient of skewness close to 0

- Linear approximation models provide a change from the Black-Scholes model is consistent with the value of the skewness is different for the same interest rate

- European call option pricing model with the linear approximation has a small enough difference with the price of the option in the market compared to other models when the exercise price is less than the strike price. In contrast to the European call option price approximation linear models have a considerable difference to the price of the option in the market compared to other models when the exercise price is more than the strike price. Thus the linear approximation of the model is suitable for the writer or the holder to make a decision if the exercise price is less than, close to or nearly equal to the strike price. The application program developed can be used to real application confidently with high security

\section{REFERENCES}

Andriyanto, 2009. Model investasi harga saham tipe eropa dengan menggunakan model black-scholes. Unpublished Thesis, University of Yogyakarta, Indonesia.

Choi, S.Y., J.P. Fouque and J.H. Kim, 2013. Option Pricing under hybrid stochastic and local volatility. Quantitative Finance, 13: 1157-1165.

Floroiu, O. and A. Pelsser, 2012. Incomplete-market prices for options. Social Science Research Network.

Gerber, H.U. and B. Landry, 1997. Skewness and stock option prices. North Am. Actuarial J., 1: 50-115. DOI: 10.1080/10920277.1997.10595627 
Gerber, H.U. and E.S.W. Shiu, 1994. Option Pricing by esscher transforms. Trans. Soc. Actuaries, 46: 99191.

Mcleod, H.I., H. Yu and E. Mahdi, 2012. Time Series Analysis with. In: Handbooks of Statistics $30 \mathrm{R}$, Rao, T.S., S.S. Rao and C.R. Rao (Eds.), Elsevier, Amsterdam.

Pradhitya, K.A.S., B. Susanto and H.A. Parhusip, 2012. Perhitungan harga opsi eropa menggunakan metode gerak brown geometrik. Proceedings of the Fakultas Sains dan Matematika, (SM '12), Kristen Satya Wacana University.

Ruban, O.A., L. Vitiello and S.H. Poon, 2010. Actuarial transform pricing. Social Science Electronic Publishing, Inc.
Soesanto, A.S. and A. Kaudin, 2008. Menguji akurasi black-scholes option pricing model untuk menilai opsi saham di Indonesia. J. Manage. Bus. Rev., 5: 109-118.

Staum, J., 2007. Incomplete Market. In: Handbooks in Operations Research and Management Science: Financial Engineering: Financial Engineering, Birge, J.R. and V. Linetsky (Eds.), Elsevier, Amsterdam, ISBN-10: 0080553257.

Verchenko, O., 2010. Testing option pricing models: Complete and incomplete markets. Social Science Electronic Publishing, Inc.

Yao, A.S.A.Y., 2001. State price density, esscher transforms and pricing options on stocks, bonds and foreign exchange rates. North Am. Actuarial J., 5: 104-117. DOI: 10.1080/10920277.2001.10596002 